\title{
On Teaching and Learning
}

\section{Editors:}

\section{HELEN ANSELL JAMES WILKINSON}

On Teaching and Learning publishes articles and essays on aspects of pedagogical practice and on research that has implications for teaching.

Subscription requests, letters and proposals for articles or essays should be addressed to the Editors, Derek Bok Center for Teaching and Learning, Science Center, Room 318, Harvard University, Cambridge, MA 02138

Published by the Derek Bok Center for Teaching and Learning James Wilkinson, Director

Copyright (C) 1992 by the President and Fellows of Harvard College All rights reserved.

Design: Kristine Waldman 


\section{The Revision Process: A Tool for Conceptual Development}

Sara E. Rimm, Dana B. Markow, \& Marie T. Balaban 1

1 - 1 ecent debates over the place of writing in the undergraduate curriculum have not gone unnoticed in psychology. Although Calhoun and Selby (1979) suggested that a separate course on writing in psychology be added to the requirements for psychology majors, the more popular current view advocates writing "across the curriculum." Integration of writing into the curriculum of a specific field, such as psychology, provides the student with a context for the development of writing skills. In addition, students' knowledge of the discipline can be improved through the use of writing exercises (Spiegel et al., 1990); thus, from the writing-across-the-curriculum view, learning to write complements writing to learn.

According to Light (1992), there is a strong relationship between the amount of writing and the student's level of engagement in a course. The level of engagement can be measured by time devoted to the course, the degree of intellectual challenge to the student, or the student's expressed interest in the subject. Light reported that students' level of engagement was more strongly related to the amount of writing than to other factors such as class size or the reason the student enrolled in the course.

In order to improve student writing skills and conceptual competence, we have modified the writing requirements in the undergraduate psychology course, Human Development. Approximately 50 students typically enroll in this course each year. Students come to the course with diverse backgrounds: they range from psychology concentrators to non-concentra-

MARIE T. BALABAN is an Assistant Professor in the Psychology Department at Harvard University. DANA B. MARKOW and SARA E. RIMM are graduate students in the Psychology Department and have participated in the Writing Fellows Workshop at the Derek Bok Center for Teaching and Learning. 
tors and from freshman through seniors. The course focuses on research findings and theoretical perspectives in the study of infant, child, and adolescent development.

The initial idea for the structure of one of our writing assignments came from the Graduate Writing Feillow Program offered by the Derek Bok Center on Teaching and Leaming. This program was designed to train Teaching Fellows to become effective writing instructors; it met for a two-day orientation in the beginning of the semester and once a month thereafter. The Teaching Fellows and Sue Lonoff, workshop leader, discussed how to bring writing into the classroom more effectively and how to provide constructive feedback on students' work. Teaching Fellows were encouraged to focus their comments on the content of the students' papers. This content-oriented approach was based on the belief that many initial difficulties with the structure and mechanies of writing can be corrected once the students have a better understanding of what they are trying to say. Another suggestion from these workshops was to enhance the writing process by incorporating revisions of an assigned paper into the course plan.

There are several advantages to the draft and revision process. The final paper is less likely to be a last-minute product that reflects an underdeveloped train of thought. Instead, the paper is more likely to include solidly developed ideas. The student receives initial feedback on his or her ideas and on how well those ideas are expressed. Because the feedback is geared toward improvement of the final paper and the first draft is not graded, the instructor's comments can be accepted as non-threatening. The time between the draft and final paper allows for the incubation of ideas and for a fresh approach when the student reviews his or her paper a week later. Finally, the revision process is representative of writing beyond the undergraduate years in academic and other professions: Integration of the draft and revision process into a course helps to dispel what Dubrow (1984) described as the "myth" of the brilliant last-minute job" through emphasizing the important role of revision in the writing process. In this paper, we describe our implementation of the revision process for one of the writing assignments in this course.

An instructor in developmental psychology immediately faces a fork in the curricular road: should the course be organized in a chronological manner, addressing development from infancy through childhood and adolescence, or should the course be organized topically, covering physical development, cognitive development, social development, etc.? Each option has advantages and disadvantages. The existence of two competing strategies is useful pedagogically, because after adopting one strategy for the organization of the course, readings, and lectures, you then can ask the students to reorganize what they have learned according to the other strategy. In this way, the students make conceptual advances on their own as they interpret the course materials within a new framework.

In our chronologically-organized course, the paper draft and revision was assigned upon completion of chapters and lectures on development during early, middle, and late infancy. Students were asked to select one of the following topics in infant development: memory, temperament and emotions, or sense of self and egocentrism, and write a 4- to 5-page essay describing the important developmental changes within the selected topic area. In other words; we asked students to reorganize information that they had learned chronologically into a topically-organized paper.

We did not want students simply to provide a summary of relevant information presented in each chapter. In order to emphasize the conceptual nature of the paper, our instructions further explained that students should (a) consider what competencies the child shows at the end of infancy, (b) evaluate evidence for the importance of continuous versus discontinuous views of development or the relative emphasis on nature versus nurture and (c) include relevant empirical evidence and, if applicable, compare various theoretical views on infant development within the selected topic area. Students were instructed to include their own opinions and insights along with ideas from the assigned course readings. 
In addition to promoting the integration of ideas presented in readings and lectures, we emphasized each student's generation of his or her own conceptual framework for the paper to reduce the likelihood of unintentional plagiarism. Price (1990) commented on the impetus for unintentional plagiarism, stating that students often "appropriated unattributed sentences and paragraphs in the naive belief (and habit, they reported) that good papers were merely good compilations" (p.52). We attempted to minimize this problem in our essay assignment. Students' selection of one of three specified topics, specification of a theme, and inclusion of their own opinions, combined with the process of draft and revision, led to relatively distinct individual papers.

The entice process of writing and revising occurred over a three-week period. Students were instructed to submit a rough draft of the paper a week after the assignment was distributed. Although the first drafts were not graded and not mandatory, we strongly encouraged students to submit them. We also emphasized that the process of revising this paper would entail more than simple editing changes and corrections. One week after they were tumed in, the papers were returned with suggestions for improvement. The students revised their essays and submitted final papers the following week.

One question is whether the first drafts should be mandatory. For this assignment, approximately $80 \%$ of the students completed initial drafts. The few students who elected not to submit a first draft of this assignment tended to receive lower grades on the final paper, often because their paper strayed from the specifications for the assignment. Does this observation indicate that first drafts should be strictly required? We prefer to keep the draft optional but provide strong encouragement for its submission. In our view, formally incorporating the writing of drafts into the syllabus should convey the inherent value of the revision process yet maintain the students' personal responsibility for their work

\section{Beriefits of Self-Assessment Reviews}

On the day that the first drafts of the papers were collected, about 10 minutes of class time was devoted to completing a self-assessment form obtained from the Graduate Writing Fellows Program at the Derek Bok Center. Students wrote responses to the following:

1. In one sentence, what is the point that you are trying to make in your essay?

2. If you had additional time to work on it, would you want to change it? Add something? Take something out? Explain.

3. What did you like most about your essay?

4. What did you like most about this assignment? What did you like least?

5. Ask one question about your essay. Design your question to elicit feedback on a specific point that will help you to revise your draft.

This self-assessment questionnaire benefited both the students and the Teaching Fellows. Students had an additional opportunity to convey the main idea of their papers, indicate areas that they thought needed improvement, emphasize what they, liked about their work, and ask specific questions about the essay. In return, this information allowed the Teaching Fellows to address the students' specific concerns about their work. The self-assessment created a dialogue between student and the Teaching Fellow which focused on the student's paper. The student took the time to evaluate the strengths and weaknesses of his or her own writing. Usually, the student's assessments closely mirrored the Teaching Fellow's concerns.

In writing comments on a draft, three of the self-assessment questions (numbers 1, 2, and 5) were particularly helpful. The response to the question, "In one sentence, what is the point that you are trying to make in your essay?" highlighted for the Teaching Fellows and the students the essence of what the 
student was attempting to say in the paper. Difficulties in answering this question provided material for the student to consider while answering the remaining self-assessment questions and while revising the paper. The Teaching Fellow integrated the information from this question into comments on the draft, addressing the main point as articulated on the selfassessment, as well as the main point in the essay itself.

The responses to question 2, "If you had additional time to work on it would you want to change it?" and to item 5, "Ask one quiestion about your essay" were especially helpful, to Teaching . Fellows in formulating comments attuned to the student's perspective on the paper. We examined students' responses to these questions in order to determine the issues of particular importance. Most students expressed an intention to add to their essay during the revision, and most questioned whether they had provided enough supporting evidence for their argument. Most students also had concerns about the focus of their paper. Some wanted to know if their theme was wellarticulated, whereas others had difficulty finding the overall theme of their paper. Related issues raised in these questions centered on the coherence and integration of the essay's argument. Students took the opportunity to ask content-related questions as well as format questions (e.g., how to handle references).

Although the composition of responses to a self-assessment questionnaire will vary depending upon the individual demands of the assignment, we believe that some issues, such as the focus and construction of an essay's argument, are relevant for writing in most disciplines. Our review of the selfassessment responses indicated that these core aspects of good composition are of concern to the students as well as the teachers.

\section{A Specific Example of the Revision Process}

One student, who selected the topic of temperament and emotions, stated her main point on her self-evaluation form: "Although emotions and temperament are both parts of social development, they develop differently in terms of continuity and nature vs. nurture." She also mentioned, "I don't really have a specific thesis to argue $I$ just showed the differences [between temperament and emotions]. How can I reformulate the paper to have a more specific thesis?" Statements from the opening paragraph of the first draft illustrate the student's difficulty in articulating her thesis:

Emotions and temperament are two opposite sides of the social development coin. Expression of emotions is a means of communicating individual temperamerit and needs; but besides this relationship between emotions and temperament, there are many differences between emotions and temperament on a developmental basis. In terms of continuity and discontinuity and nature versus nurture, tem-

perament and emotions lean towards one side or the other.

The Teaching Fellow, Sara Rimm, commented on the validity of the student's thesis: "I disagree with your main argument. Temperament and emotions are more alike than they are different. Look back in your notes and consider the readings in your text. Perhaps you should consider the biological underpinnings of emotional expression and temperament in order to reformulate your thesis statement. Do emotions really develop in discrete stages?"

These content-oriented comments were designed to help the student develop her thesis based on information in the course that emphasized the relationship between temperament and emotions. A secondary motive of the comment was to remind her of the question to be addressed. We did not ask her to contrast the constructs of temperament and emotionality, but rather to consider the two topics as they relate to each other in development and as they each pertain to the continuity versus discontinuity and nature versus nurture themes.

The originally vague thesis in the paper prevented the student from creating a solid argument. In the following structure-oriented comment, the Teaching Fellow responded to the student's concern as expressed on her self-assessment form and provided a scaffolding for the student's ideas: "After you present your thesis argument in your first para- 
graph, define temperament and emotions separately. Then discuss the relationship between these two constructs. After this introduction, discuss the similarities and differences between temperament and emotions (perhaps using the themes of continuous and discontinuous development or nature vs. nurture.) Allow one (or both) of these themes to guide you through your paper. Think about your transitions from paragraph to paragraph. Try to present your argument in a more continuous manner so that each paragraph addresses the main point you are trying to make."

Additional comments applauded the student's appropriate use of empirical evidence and her enthusiasm for the topic. The Teaching Fellow also commented on an unclear conceptual relationship between temperament and personality, which the student presented in her paper. Finally, the student was invited to speak to the Teaching Fellow about any problems that she faced in completing the final version of the paper.

After receiving these comments, the student did make an appointment to meet with the Teaching Fellow to review the feedback. They discussed the conceptual relationship between temperament and emotionality. Together, they considered the revision of the student's paper and talked about possible improvements. Specifically, they focused on the transitions between paragraphs and on the continuity of the major themes.

In the student's final paper, she developed a solid thesis that was reinforced throughout her essay.

Her original first paragraph, as we have seen, read:

Emotions and temperament are two opposite sides of the social development coin. Expression of emotions is a means of communicating individual temperament and needs, but besides this relationship between emotions and temperament, there are many differences between emotions and temperament on a developmental basis. In terms of continuity and discontinuity and nature versus nurture, temperament and emotions lean towards one side or the other.

The first paragraph of her final paper now read:
Emotions and temperament are two key aspects in infants' ability to respond to their environment. There is a distinct interaction between emotions and temperament as well. Emotions are a means of communicating individual needs as well as expressing natural temperament, while temperament guides behavioral arid emotional responses' to situations in the world. In terms of continuity versus discontinuity and nature versus nurture, temperament and emotions similarly lean towards continuity and the interaction of nature modified by the environment. The relationship and the similarities between temperament and emotions will be explored under the light of relevant empirical studies.

In the rest of the paper she provided supporting evidence for these statements. This much-improved final version was clearly written and demonstrated mastery of the material.

\section{The Students' Response}

At the mid-semester evaluation of the course, students expressed a generally positive opinion of the focus on writing in this course. At the conclusion of the semester, we asked a few students to elaborate on their experiences with writing for the course. We asked them to compare the written assignments in this class with the written assignments typically required in non-psychology classes and in other psychology classes. They responded that writing for psychology courses in general is "a lot more fact-based, you really have to back up what you say:" Yet, this course required "more thought" than other psychology classes. They particularly appreciated the opportunity to write three short papers compared to a long paper at the end of the term. This structure allowed them to get feedback all along and thus, "more development was allowed as a writer." They found the assignment which we have discussed in this article to be the most difficult of the three papers.

Student comments on the draft writing process reinforced our perception that students differ widely in their response to such an assignment. Some students were already accustomed 
to incorporating extensive revisions into their writing process, but other students had their first draft-writing experience with this assignment. One student, who usually writes drafts of assignments, said that the "draft" stie handed in was actually her third or fourth revision, and that as a result she was tired of the paper when it came time to write the final copy. Yet she wanted to work on the first draft as much as possible so that she could receive the most specific feedback from the Teaching Fellow. Another student who usually does not write extensive first drafts of papers said that "the process was good in retrospect," and indicated that if draft-writing had not been incorporated as part of the course she would not have written an initial draft. A third student welcomed the draft process because it allowed her to devote more time to the paper and because it offered additional opportunity for revision.

The students found the self-assessment sheet to be especially helpful. The questions helped them focus on what they. were trying to convey: "I could tell you (the Teaching Fellow) what I was confused about. . . what I needed help with. .." Another student said that when the teacher provides comments on a paper the student does not have to think; however, the self-assessment sheet makes the student reflect on her own writing. Because of this, the students suggested that the self-assessment sheet be distributed with the original assignment, as a cover sheet, so that they could keep the questions in mind while they write. They particularly appreciated the first two questions, but thought that the question concerning what they liked about their paper was somewhat difficult to answer.

\section{The Teaching Fellows" Response}

A writing intensive course requires additional work on the part of Teaching Fellows as well as of the students. Teaching Fellows must read and comment on each assignment twice, and comments on first drafts tend to be specific and extensive since this feedback is an important part of the entire process. However, we believe that the benefits of a writing-focused course outweigh the costs of an increased workload. We preferred commenting on the drafts before evaluating final papers, because reviewing papers is a more satisfying experience when earlier suggestions have had an impact on the quality of the finished assignment. The selfassessment sheets completed by the students allow the Teaching Fellow to make more specific suggestions and to understand the thought processes underlying the student's work. The draft process also helps the Teaching Fellow to focus on the writing itself, and not only, on evaluation for grades. Of course the ultimate benefit is the student's improvement in writing and advances in conceptual proficiency. We have been able to read some wonderful papers as a result of participating with students in this writing process.

\section{The Professor's Response}

The process of writing a draft and accomplishing a revision promotes individual communication between the student and the Teaching Fellow. The written feedback provided by the Teaching Fellow is integral to the revision process; it also provides a tangible basis for discussion. During the weeks of this assignment, there is a welcome flurry of office hour activity. There is, at least for many participants, a spirit of camaraderie in working toward the completed product. Called to mind are the related Latin words from which our word "assessment" derives: "assidere", meaning to sit beside, and "assessor," one who helps to judge.

Students who are novices in a particular area, such as developmental psychology, typically find it easier to espouse one of two polarized views rather than work to balance the worthwhile contributions of several perspectives. In this process of writing and revising drafts, the comments from the Teaching Fellows enabled students to reevaluate their originally-stated, often reductionistic and polarized views, and, as 
Price (1990) described, to discover connections between seemingly unrelated concepts. This reexamination is certainly indicative of "writing to learn" within the curriculum.

\section{Notes}

1 We gratefully acknowledge the help of Sue Lonoff, Associate Director of the Derek Bok Center for Teaching and Learning. We tharik Mary Mulien, a teaching fellow for this course in 1990-91, for bringing the Graduate Writing Fellows Program to our attention and for playing an instrumental role in incorporating the revision process into the written assignments for this courise. We are grateful to the students, including Eileen Kim, Wendy Etheridge, and Kathleen Wall, for their comments on this assignment. As advocates of the draft and revision process, we also gratefully' acknowledge Sandra R. Waxman for her collegial comments on a draft of this paper.

\section{References}

Calhoun, L. G. \& Selby, J. W. (1979). Writing in Psychology: A separate course? Teaching of Psychology, 6,232

Dubrow, H. (1984). Teaching essay writing in a liberal arts curriculum. In M. M. Gullette (Ed.), The Art and Craft of Teaching. Cambridge, MA: Harvard University Press.

Light, R. J. (1992). The Harvard Assessment Seminars: Explorations with students and faculty about teaching, learning, and student life. Second report of the Harvard University Graduate School of Education and Keninedy School of Government.

Price, D. W. W. (1990). A model for reading and writing about primary sources: The case of introductory psychology. Teaching of Psychology, 17, 48-53.

Spiegel, T. A., Cameron, S. M., Evans, R., \& Nodine, B. F. (1980). Integrating writing into the teaching of psychology: An alternative to Calhoun and Selby. Teaching of Psychology, 7, 242-243. 